\title{
ИНСТИТУЦИОНАЛЬНЫЙ ПОДХОД К УПРАВЛЕНИЮ РАЗВИТИЕМ ТЕРРИТОРИИ МУНИЦИПАЛЬНЫХ РАЙОНОВ ВОРОНЕЖСКОЙ ОБЛАСТИ
}

\author{
Е.С. Кулаковский \\ Санкт-Петербургский государственный университет, Россия \\ Поступила в редакиию 6 мая 2019 г.
}

\begin{abstract}
Aннотация: Статья посвящена анализу управления развитием муниципальных районов Воронежской области. Показано, что ведущее место в определении ограничений и приоритетов субъектов управления принадлежит институтам. Выделены институциональные структуры местного самоуправления, к которым относятся распределительные (финансово-бюджетные), трансформационные (инвестиционные) и организационные (нормативно-правовая база) процессы. Использованы элементы теории географической экспертизы для выявления слабых мест в системе принятия управленческих решений: финансово-бюджетное несовершенство, низкая инвестиционная привлекательность, шаблонный подход к принятию управленческих решений. Установлено, что эти несовершенства создают условия для низкой мотивации властных структур и высокого риска экономических агентов. Обоснована возможность и необходимость использования институциональных структур при разработке документов, определяющих стратегию региональной политики в Воронежской области, в частности схем территориального планирования муниципальных районов.
\end{abstract}

Ключевые слова: социальный институт, местное самоуправление, географическая экспертиза, финансы, инвестиции, пространственное планирование.

Institutional approach to managing the municipal districts area development in the Voronezh region

\section{E.S. Kulakovskiy}

Abstract: The article is devoted to the analysis of the development management of municipal districts of the Voronezh region. It is shown that the leading place in determining the limitations and priorities of the subjects of management belongs to the institutions. Institutional structures of local self-government have been identified, which include distribution (financial and budgetary), transformational (investment) and organizational (regulatory and legal) processes. The elements of the theory of geographical expertise were used to identify weaknesses in the system of making management decisions: fiscal imperfection, low investment attractiveness, a patterned approach to making management decisions. It has been established that these imperfections create conditions for low motivation of power structures and high risk of economic agents. The possibility and necessity of using institutional structures in the development of documents defining the strategy of regional policy in the Voronezh region, in particular, territorial planning schemes of municipal districts, are substantiated.

Key words: social institution, local government, geographical expertise, finance, investment, spatial planning.

() Кулаковский Е.С., 2019

Материал статьи доступен по лицензии

Creative Commons "Attribution" 4.0 


\section{Е.С. Кулаковский}

\section{ВВЕДЕНИЕ}

Деятельность институтов на региональном и муниципальном уровнях при принятии управленческих решений обусловлены рядом обстоятельств: спецификой местной нормативно-правовой базы; обоснованием направлений развития территорий, исходя из финансовых возможностей субъектов управления; приоритетов и ограничений функционирования ключевых акторов (бизнес, государство, общественные структуры). Параллельно с формированием муниципальной системы развиваются и другие институты: стратегическое пространственное планирование [8], межбюджетные отношения [6], институт собственности [11] и другие. Использование институционального подхода к обоснованию развития регионов позволяет выявить - до какой степени и каким образом нормативно-правовая база, экономические агенты и местное сообщество определяют процессы неравномерной экономической деятельности $[25,27]$.

\section{ИЗУЧЕННОСТЬ ПРОБЛЕМЫ}

Первоначальное внимание к институтам было вызвано необходимостью объяснения социальноэкономической дифференциации регионов мира: это - рывок в экономике и технологиях одних государств (США, Япония, Китай) и отставание развивающихся государств. Чаще всего сторонники институционального подхода дифференциацию регионов и стран объясняют различиями в реализации общественных правил и норм $[21,22]$, что в общих чертах позволяет раскрыть причины экономического роста одних и отставания других субъектов управления. Этот подход необходимо рассматривать вместе с географическими факторами [19].

Начиная с 1993 года, в России формируется местное самоуправление, но его функционирование вызывает в большинстве случаев отрицательную оценку $[3,12,18]$. Объяснение этому факту следует искать в использовании чужеродного опыта института и игнорировании местных реалий. В связи с этим автор считает актуальным анализ результатов, принимаемых в РФ (и, в частности, в Воронежской области) управленческих решений, особенно в части выявления внутренних противоречий, что позволяет определить актуальные направления в региональной политике [16]. Для решения данного вопроса наилучшим образом подходят теоретико-методологические положения географической экспертизы, разработанные К. П. Космачевым. Суть его концепции заключается в оценке соответствия тенденций развития сложных территориальных систем «природа - общество - хозяйство» реалиям действительности [5], что позволяет раскрыть сущность деятельности институтов

Состав и критерии оценки институциональных структур развития территорий

Таблиия 1

\begin{tabular}{|l|l|l|}
\hline $\begin{array}{c}\text { Институциональные } \\
\text { структуры }\end{array}$ & \multicolumn{1}{|c|}{ Содержание оценки } & \multicolumn{1}{|c|}{ Критерии оценки структур } \\
\hline Распределительная & $\begin{array}{l}\text { Система распределения средств } \\
\text { между субъектами управления } \\
\text { (финансово-бюджетные и } \\
\text { налоговые процессы) }\end{array}$ & $\begin{array}{l}\text { Структура доходов и расходов } \\
\text { бюджета. } \\
\text { Доля собственных доходов. } \\
\text { Соотношение доходной и } \\
\text { расходной части бюджета - } \\
\text { профицит / дефицит. }\end{array}$ \\
\hline Трансформационная & $\begin{array}{l}\text { Преобразование поступающих } \\
\text { средств (инвестиции); } \\
\text { приоритеты экономических } \\
\text { агентов (государство, бизнеса и } \\
\text { домохозяйств) в региональной } \\
\text { политике }\end{array}$ & $\begin{array}{l}\text { Инвестиции на душу населения. } \\
\text { Инвестиции в основные фонды. } \\
\text { Малый и средний бизнес (число } \\
\text { предприятий на количество } \\
\text { населения и удельный вес } \\
\text { занятых) }\end{array}$ \\
\hline Организационная & $\begin{array}{l}\text { Нормативно-правовая база в } \\
\text { развитии территорий } \\
\text { (стратегическое }\end{array}$ & $\begin{array}{l}\text { Управленческие решения } \\
\text { оцениваются на основе } \\
\text { петодологии географической } \\
\text { пространственное планирование } \\
\text { регспертизы [8] и привлечения } \\
\text { прональные и муниципальные } \\
\text { программы) }\end{array}$ \\
$\begin{array}{l}\text { практических наработок в этом } \\
\text { направлении [4] }\end{array}$ \\
\hline
\end{tabular}


через результаты принимаемых управленческих решений [10].

Изучение роли социальных институтов в российских регионах получило отражение в трудах Р. М. Нуреева [9] и В. М. Полтеровича [11] по институциональной экономике; Ю.Н. Баженова и А. И. Чистобаева, посвященных программно-целевому управлению и планированию [20]; Н. Ю. Замятиной и А.Н. Пилясова по региональному консалтингу [4]; Е.Г. Анимицы [1], О. Б. Глезер [3], Н. М. Сысоевой [15], посвященные анализу влияния деятельности местного самоуправления на другие формы территориальной организации общества.

\section{МЕТОДОЛОГИЯ И МЕТОДИКА ИССЛЕДОВАНИЯ}

Ключевым термином данного исследования является институт, под которым понимается объединение людей и ресурсов в рамках социально признанных объединений в частном и государственном секторах [25]. Иными словами, это «правила игры» в обществе, то есть формально созданные человеком ограничительные рамки [22]. В управлении развитием территории деятельность институтов выражается через категорию «институциональные структуры». Под такими структурами понимается совокупность упорядоченных определенным образом институтов, образующих единое целое с акцентом на оценку ограничения и приоритетов ключевых экономических агентов (государство, бизнес и общественные структуры) в развитии регионов.

Исследуя российские регионы, Н. М. Сысоева выделяет три вида институциональных структур: распределительные, трансформационные и организационные [24]. В диссертации Р. Е. Рогозиной по Воронежской области содержание этих структур нацелено на практику планирования и программирования [14]. Суммируя подходы Н. М. Сысоевой и Р. Е. Рогозиной, автором предлагается следующий состав институциональных структур в управленческих решениях (таблица 1).

Рассматриваемые структуры обладают следующими чертами: 1) пространственной локализацией (вовлеченностью институтов в деятельность регионов); 2) инерционностью действия институтов, что определяет границы их участия в координации и непрерывности экономической деятельности; 3) креативностью, то есть спецификой продвижения инноваций самой средой $[23,24]$. В данном исследовании автор рассматривает специфи- ку институциональных структур на муниципальном уровне Воронежской области.

Сложности в рассмотрении институциональных структур обусловлены спецификой институтов и неоднозначностью в определении групп влияния на развитие регионов. В целях достижения репрезентативности полученных на основе критериев оценки результатов автором использованы средние значения за три года (2014-2016 гг.), что позволяет исключить конъюнктурные влияния.

Одним из методологических нюансов исследования является выявление групп влияния в экономике через определение как доли малого и среднего бизнеса, так и крупных холдингов в экономике муниципальных районов. Такой подход позволяет определить территории с наилучшими условиями ведения бизнеса, дает основание проследить изменения налогооблагаемой базы.

Использование географической экспертизы сопряжено с привлечением качественной методологии с акцентом на следующие «критерии»: целеполагания (отражает генеральные цели в социально-экономическом развитии территорий); анализа сложившейся ситуации (с учетом полноты анализируемой информации); обоснования предложенных мероприятий и возможности их реализации; вариантности изменения сложившейся ситуации. Дополнительно стоит обратить внимание на используемые в документах понятия и термины.

\section{РЕЗУЛЬТАТЫ ИССЛЕДОВАНИЯ И ИХ ОБСУЖДЕНИЯ}

\section{Распределительные структуры}

Финансовую составляющую регионов невозможно оставить в стороне от рассмотрения из-за их вовлеченности в вопросы функционирования субъектом управления. Так, большинство бюджетов муниципальных районов Воронежской области отличаются дефиичтнностью и низкой долей собственных доходов; около 1/3 бюджетов дефицитны, еще столько же имеют низкую долю собственных доходов (до 40\%) (рис.1).

При детальном рассмотрении муниципальных бюджетов проявляется ряд противоречий. Во-первых, в одну группу дефицитных бюджетов попадают как районы с относительно высоким уровнем социально-экономического развития (Лискинский район), так и с низким уровнем (Нижнедевицкий район). Во-вторых, в муниципальных районах, имевших высокое значение инвестиций, происходит снижение доли собственных доходов (Лискинский и Рамонский). В-третьих, снижение 


\section{Е.С. Кулаковский}

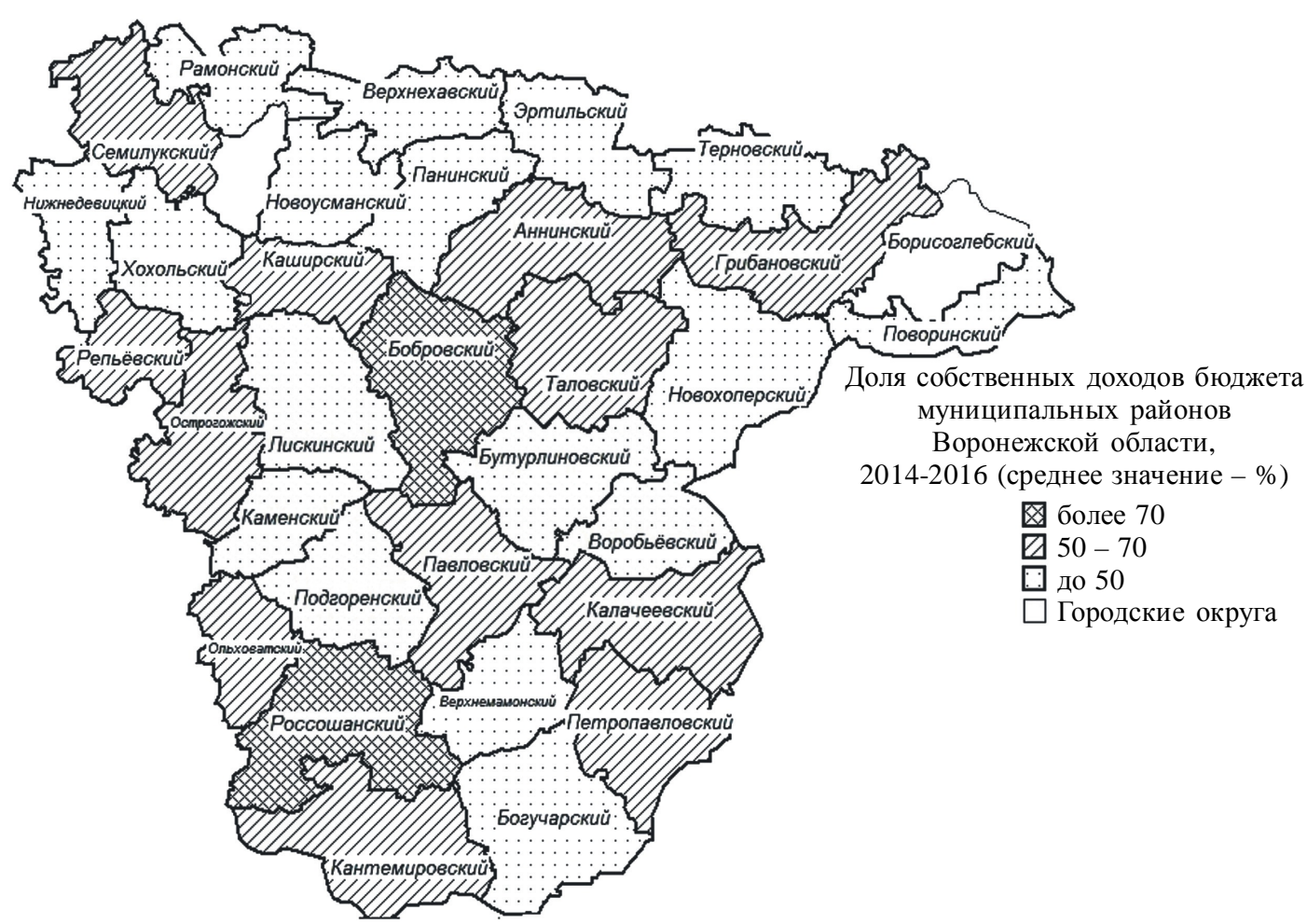

Puc. 1. Бюджетная специфика муниципальных районов Воронежской области, 2014-2016 годы (средние значения)

дефицита районных бюджетов происходит на фоне увеличения долговых обязательств.

Нехватка собственных средств толкает органы государственной и муниципальной власти прибегать к заимствованиям, что приводит к росту внут реннего долга области и муниципальных образований. Эта проблема отражает незрелость отечественной финансовой системы, которая выражена в несовершенстве распределения налогов, большая часть которых уходит в федеральный центр. Небольшая часть налогов, поступающая в местные бюджеты, крайне сложно собирается, особенно с учетом преференций для отдельных категорий населения.

Интенсивный рост долга регионов и муниципальных образований (рис. 2) пришелся на период после 2012 года, что объясняется реализацией майских указов Президента РФ, исполнение которых легло на региональные и местные бюджеты. Ситуация усугубилась последовавшими санкциями и социально-экономическим кризисом. По этим причинам снизилось финансовое положение предприятий, что вызвало рост убыточных предприятий до $1 / 3$ от общего числа предприятий в регионе. Распределительные структуры отражают проявление социально-экономического кризиса.
Трансформачионные структуры

Трансформационные структуры отражают приоритеты бизнеса, государства и общественных структур в развитии территорий.

Ключевой «поведенческой» установкой в деятельности экономических агентов региона является размещение государственными корпорациями и федеральным бизнесом производственных площадок в Воронежской области с отсутствием штабквартир или представительств этих структур. Данную тенденцию можно обозначить как «филилализация региона», которая влияет на уплату целого ряда налогов по месту регистрации предприятий (в частности, налога на прибыль организаций).

Оценить потери от размещения центра регистрации предприятий на муниципальном уровне можно на примере отдельных муниципальных образований Воронежской области, в частности на примере городского округа город Нововоронеж. Размещение обособленных структур Росатома (на время строительства новых энергоблоков Нововоронежской АЭС-2) увеличило налог на прибыль более, чем в 1,5 раза. Одной из проблем является налоговая централизация, в которой отсутствуют стимулы в развитии регионов.

В Воронежской области все больше усиливается монополизация экономики вследствие повы- 


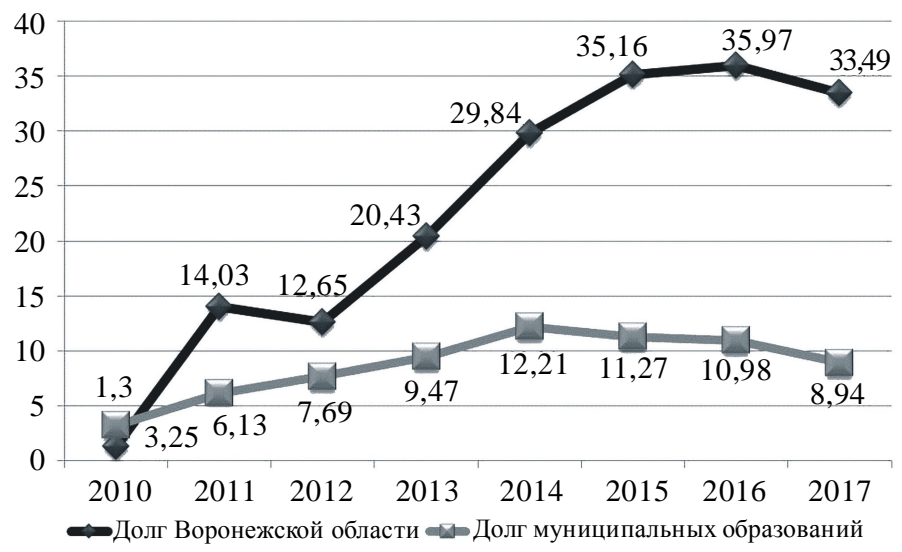

Puc. 2. Динамика внутреннего долга Воронежской области и муниципальных образований, 2010-2017 годы

Таблича 2

Группы влияния в отдельных отраслях Воронежской области

\begin{tabular}{|l|l|l|}
\hline \multicolumn{1}{|c|}{ Комплекс отраслей } & \multicolumn{1}{|c|}{ Отдельные отрасли } & \multicolumn{1}{|c|}{ Примеры крупных холдингов } \\
\hline $\begin{array}{l}\text { Агропромышленный } \\
\text { комплекс }\end{array}$ & $\begin{array}{l}\text { Молочное } \\
\text { производство }\end{array}$ & $\begin{array}{l}\text { «Молвест» (Воронеж, Богучар, Калач, } \\
\text { Новохоперск, Хохольский), Доминант } \\
\text { (Лиски) }\end{array}$ \\
\cline { 2 - 3 } & Сахарное производство & $\begin{array}{l}\text { Продимекс } \\
\text { АСБ (Грибановский) }\end{array}$ \\
\hline Химический комплекс & $\begin{array}{l}\text { Сибур (Воронежсинтезкаучук), } \\
\text { Национальная химическая компания } \\
\text { (Минудобрения Россошь) }\end{array}$ \\
\hline Розничная торговля & $\begin{array}{l}\text { Магнит, Х5 Retail group (торговые } \\
\text { бренды Пятерочка, Перекресток, } \\
\text { Карусель) }\end{array}$ \\
\hline
\end{tabular}

шения доли крупных финансово-промышленных групп, которые активно вытесняют другие экономические агенты, включая малый и средний бизнес. Эта тенденция охватывает практически все секторы экономики, причем наибольшую роль она приобретает в агропромышленном комплексе. Монопольные структуры усиливают кризисные черты на рынке труда.

В качестве иллюстрации негативных проявлений монопольных структур в экономике региона можно привести ООО «Продимекс», которому принадлежит основная часть сахарного производство в регионе (8 из 9 сахарных заводов), а также компании по хранению и переработке зерна. В конце 2018 года было объявлено решение о закрытии одного из предприятий, принадлежащих «Продимексу» - Садовского сахарного завода. Компания участвовала в решении проблемы трудоустройства сотрудников только после вмешательства областного правительства: большинство уволенных работников нашло себе место на других производствах. В регионе действуют и другие крупные иг- роки в агропромышленном секторе, химическом комплексе и розничной торговле (таблица 2).

Привлечение инвестиций и малый бизнес, помимо монополизации экономики, испытывают множество других рисков: это - коррупция, рейдерство, уход бизнеса в тень. В связи с этим важно оценивать органы государственной и местной власти именно с позиции повышения инвестиционной привлекательности и доли малого бизнеса.

Специалисты оценивают численность занятых в теневом секторе в пределах 200 тысяч трудоспособного населения. Большая доля теневого сектора показывает своеобразную незрелость в экономической ситуации - проще и легче уйти в тень, чем работать в правовом поле государства [7].

Инвестиции служат основой для трансформации социально-экономической ситуации, в том числе выхода регионов из глубокого системноструктурного кризиса. В Воронежской области интерес инвесторов вызывают следующие отрасли: электроэнергетика $(27,4 \%)$, обрабатывающие производства $(21,0 \%)$, сельское хозяйство $(17,7 \%)$, 


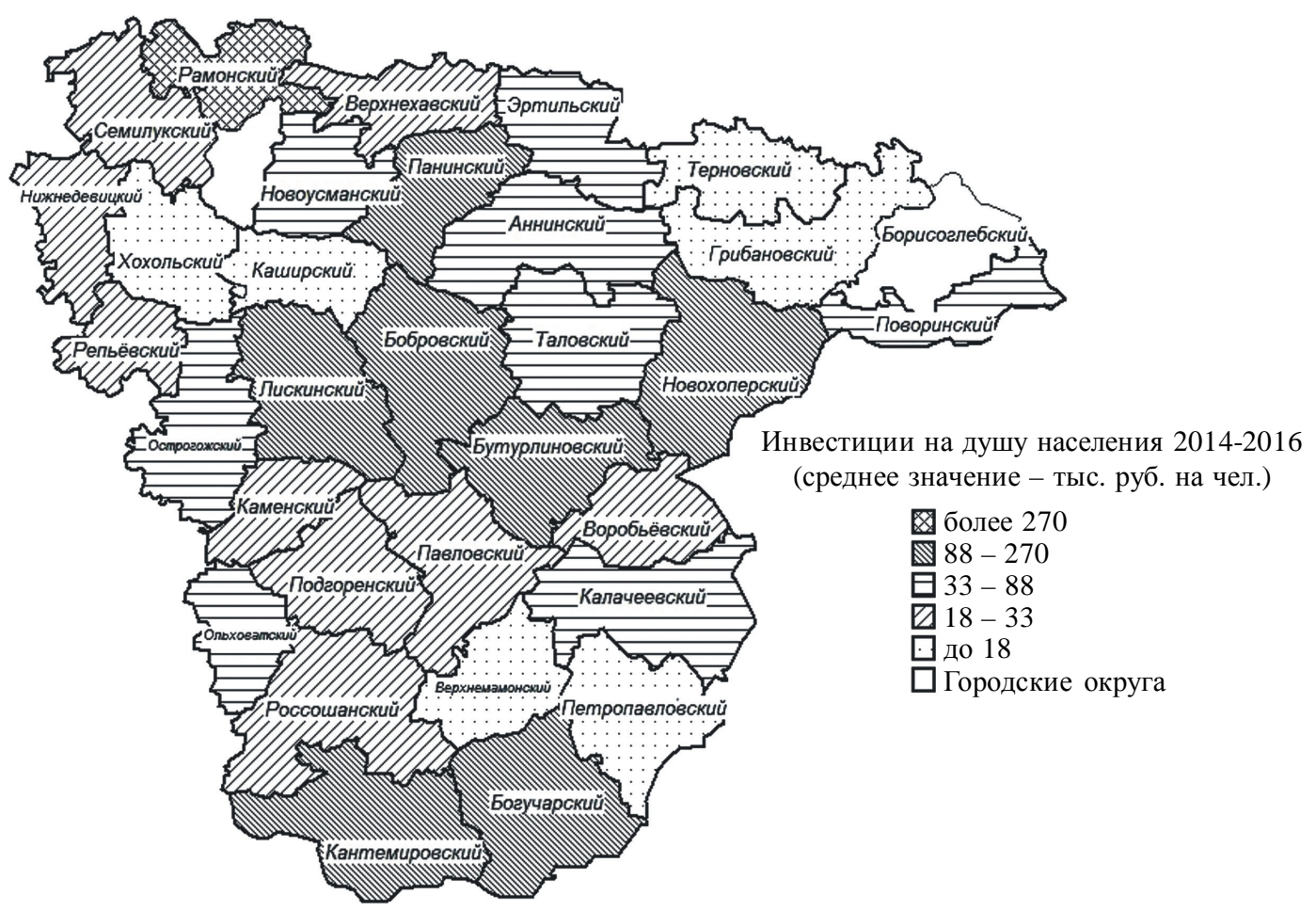

Puc. 3. Инвестиции на душу населения муниципальных районов Воронежской области, 2014-2016 годы (средние значения)

транспорт и связь $(13,4 \%)$. Основными инвесторами, по данным на 2016 год, являются частные $(52,4 \%)$ и государственные $(34,5 \%)$ структуры, причем государство активнее всего участвует в инфраструктурных проектах.

Большинство периферийных муниципальных районов имеют низкую инвестиционную привлекательность, особенно это относится к Петропавловскому и Верхнемамонскому (рис. 3). Более высокая инвестиционная привлекательность определяется, во-первых, реализацией крупных проектов (например, строительство железной дороги по территории области в обход Украины); во-вторых, развитием сельского хозяйства, в том числе с привлечением крупных холдингов; в-третьих, реализацией транспортно-логистических проектов и объектов торгового обслуживания.

Малому бизнесу принадлежит большое значение вследствие возможности его адаптации к меняющимся условиям. Однако большинству субъектов малого бизнеса присуща небольшая доля как по числу занятых, так и в расчете на душу населения (10 тыс. человек). В половине районов эти показатели не достигают среднеобластного уровня. Основными отраслями малого бизнеса является торговля, сельское хозяйство и транспорт (в совокупности на них приходится около $3 / 4$ ).
Сопоставляя роль малого бизнеса и крупных холдингов в развитии территорий, можно выявить различия по их роли в управлении. Наибольшее значение имеют районы с узкой специализацией (Грибановский, Подгоренский, Лискинский). Высокая доля малого бизнеса (вместе с диверсификацией экономической деятельности) стимулирует значительный рост в экономике и снижение возможности влияния отдельных структур на управленческие решения (Новоусманский, Семилукский, Рамонский).

\section{Организационные структуры}

Согласно Стратегии социально-экономического развития и Генеральной схеме развития и размещения производительных сил Воронежской области, ставка региональных властей сделана на три сектора экономики: торговлю, транспорт и агропромышленный комплекс [13]. Высокий уровень агропромышленной специализации свидетельствует о наличии узких мест в экономике. Очевидно, это направление необходимо дополнить повышением роли инновационных отраслей экономики, используя богатый потенциал университетов города Воронежа. Подтверждением сказанному служит создание индустриальных парков, технопарков, особой экономической зоны (ОЭЗ). Так, наметился успех в создании ОЭЗ промышленно-про- 
изводственного типа. Признаки специализации приобретают металлургическое производство, химическая промышленность, производство строительных материалов. Правительство Воронежской области заявило о семи компаниях, которые выразили готовность работать в ОЭЗ. Большим «плюсом» в ее создании является расположение вблизи существующего индустриального парка «Масловский».

Важное место в системе управленческих решений по развитию территорий занимают схемы территориального планирования, назначение которых состоит во взаимоувязке вопросов организации пространства, исходя из возможностей социально-экономической сферы [17]. Анализ действенности этой своеобразной формы управления необходимо начать с исходных позиций целеполагания, анализа современной ситуации, обоснования предлагаемых мероприятий. Особенно важное значение имеет целеполагание, направленное на снижение негативных последствий деструктивных процессов в обществе.

Проводя экспертизу предлагаемых в схемах мероприятий, можно выделить недостатки, препятствующие принятию конструктивных решений, а именно:

1) шаблонность схем, недооценка индивидуальных особенностей территории в попытке обосновать единый перечень управленческих мероприятий;

2) внесение вследствие финансово-бюджетных ограничений большего числа правок к исходным документам, в результате чего теряется суть предложений;

3) упрощенное понимание сути территориального планирования: часто разработчики сводят ее лишь к размещению материальных объектов и трактовке земельно-имущественных отношений, а не к отражению альтернативных путей развития и размещения производительных сил;

4) отсутствие применения подходов, позволяющих увидеть индивидуальные особенности территории и учесть их при решении вопросов социально-экономического развития территории;

5) попытки удержать существующую территориально-планировочную структуру, что противоречит современным социально-экономическим и демографическим тенденциям (за межпереписной период 2002-2010 годов с политической карты Воронежской области исчезло 162 населенных пункта;

6) недостаток информации в разрезе поселений, что приводит к недопониманию сложности происходящих на низовом уровне социально-экономических процессов.

В Воронежской области предприняты попытки привлечения населения к выработке стратегии развития своей территории. В качестве одного из механизмов решения этого вопроса используется инициативное бюджетирование. Этот проект реализуется на протяжении трех лет и уже можно подвести неутешительные предварительные итоги: за неполные три года выделено лишь 183,5 млн. руб. на 106 проектов, что явно недостаточно для достижения поставленной цели.

Все сказанное свидетельствует о разрыве реальности и принимаемых управленческих решений. Зачастую процессы развития происходят не благодаря, а вопреки принимаемым решениям.

\section{ВЫВОДЫ}

Использование институционального подхода к исследованию муниципальных районов позволило выявить ограничения и приоритеты ключевых агентов экономической деятельности, в том числе и их влияние на принимаемые управленческие решения.

Анализ институциональных структур Воронежской области и, прежде всего, на уровне муниципальных районов позволило выявить особенности деятельности местного самоуправления - финансово-бюджетная зависимость большинства субъектов управления в совокупности с ростом их закредитованности ограничивает возможности развития и реализации своих полномочий.

К числу актуальных проблем относятся ограничения в функционировании экономических агентов. Они проявляются в размещении преимущественно производственных площадок, монополизации, коррупции, уходе бизнеса в тень, шаблонности управленческих решений. Эти ограничения препятствуют привлечению инвестиций и развитию малого бизнеса.

Необходимость продолжения исследований институционального подхода к управлению развитием территории региона и муниципальных образований нуждается в рассмотрении вопросов межбюджетных взаимодействий между субъектами управления и участии институтов в определении стратегических направлений развития региональной политики.

\section{СПИСОК ЛИТЕРАТУРЫ}

1. Анимица Е. Г. Программно-проектный подход важнейший инструмент регулирования регионального развития / Е. Г. Анимица, Н. В. Новикова, В. А. Сухих // 


\section{Е.С. Кулаковский}

Известия Уральского государственного экономического университета. - 2008. - № 2 (21). - С. 50-57.

2. Вильнер М. Я. О критериях качества схем территориального планирования регионов / М. Я. Вильнер // Academia. Архитектура и строительство . - 2012. - № 3. - C. 82-87.

3. Глезер О. Б. Система местного самоуправления как составная часть институциональной среды расселения в современной России / О. Б. Глезер // Вопросы географии. - 2013. - № 135. - С. 224-244.

4. Замятина Н. Ю. Региональный консалтинг: приглашение к творчеству. Опыт разработки документов стратегического планирования регионального и муниципального уровня / Н. Ю. Замятина, А. Н. Пилясов. Санкт-Петербург : Маматов, 2017. - 280 с.

5. Космачев К. П. Географическая экспертиза (методологические аспекты) / К. П. Космачев. - Новосибирск : Наука, 1981. - 112 с.

6. Кузнецова О. В. Полномочия регионов и муниципалитетов в налоговой сфере / О. В. Кузнецова // Проблемный анализ и государственно-управленческое проектирование. - 2012. - Т. 5, № 6. - С. 98-104.

7. Ломсадзе Д. Г. Преодоление проблем теневой экономики / Д. Г. Ломсадзе, А. А. Болдырихин. - Воронеж : Ритм, 2018. - 77 с.

8. Одинцова А. В. Проблемы институционализации стратегического планирования муниципальных образований / А. В. Одинцова // Проблемы развития территории. - 2018. - № 5(97). - С. 99-109.

9. Нуреев Р. М. Россия после кризиса - эффект колеи / Р. М. Нуреев // Journal of institutional studies. -2011. - № 2. - С. 7-26.

10. Пилясов А. Н. Сравнительный институциональный анализ как новый инструмент исследования проблем пространственного развития / А. Н. Пилясов, Н. Ю. Замятина // Региональные исследования. - 2012. - № 6. - С. 239-250.

11. Полтерович В. М. Институты догоняющего развития (к проекту новой модели экономического развития России) / В. М. Полтерович // Экономические и социальные перемены: факты, тенденции, прогноз. - 2016. - № 5(47). - С. 34-56.

12. Поросенков Ю. В. Задачи и проблемы географического исследования муниципальных образований Российской Федерации / Ю. В. Поросенков // Вестник Воронежского государственного университета. Сер. География. Геоэкология. - 2012. - № 1. - С. 5-13.

13. Поросенков Ю. В. Региональная схема размещения производительных сил Воронежской области / Ю. В. Поросенков, О. Ю. Сушкова // Вестник Воронежского государственного университета. Сер. География. Геоэкология. - 2015. - № 2. - С. 50-57.

14. Рогозина Р. Е. Географические особенности процессов территориальной организации российского общества на рубеже XX-XXI веков : автореф. дис. ... канд. геогр. наук / Р. Е. Рогозина. - Воронеж, 2002. - 18 с.

15. Сысоева Н. М. Географическая экспертиза как вклад в развитие институционального направления в экономической географии (к 90-летию со дня рождения К. П. Космачева) / Н. М. Сысоева // География и природные ресурсы. - 2011. - № 4. - С. 157-160.

16. Чистобаев А. И. Владимир Михайлович Четыркин - теоретик проблемного районирования / А. И. Чистобаев // Известия Русского географического общества. - 2008. - № 5. - С. 1-8.

17. Чистобаев А. И. Пространственное планирование в России: состояние, проблемы, задачи географов / А. И. Чистобаев // Социально-экономическая география. Вестник Ассоциации российских географов-обществоведов. - 2013. - № 1. - С. 15-24.

18. Чистобаев А. И. Территориальная организация местного самоуправления в России / А. И. Чистобаев // География в школе. - 2014. - № 7. - С. 10-17.

19. Чистобаев А. И. Сюжеты из практики управления развитием территорий в СССР и современной России / А. И. Чистобаев // Социально-экономическая география. Вестник Ассоциации российских географовобществоведов. - 2018. - № 7. - С. 13-24.

20. Чистобаев А. И. Территориальные комплексные программы / А. И. Чистобаев, Ю. Н. Баженов. - Ленинград : Ленинградский государственный университет, 1984. -228 c.

21. Acemoglu D. Why Nations Fail: The Origins of Power, Prosperity, and Poverty / D. Acemoglu, J. Robinson. - New York : Crown Publishers, 2012. - 571 p.

22. North D. Institutions, institutional changes and economic performance / D. North. - Cambridge : Cambridge University Press, 1990. - 159 p.

23. Martin R. Institutional approaches in economic geography // A companion to economic geography / R. Martin. - Oxford : Blackwell, 2000. - P. 77-94.

24. Syssoeva N. M. Institutional problems of regional development in Russia / N. M. Syssoeva // Quaestiones Geographicae. - 2010. - № 29. - P. 19-25.

25. Wilson D. Institiutions / D. Wilson // Encyclopedia of human geography. - London : SAGE Publications, 2006. - P. 260-261.

\section{REFERENCES}

1. Animitsa E. G., Novikova N. V., Sukhikh V. A., Programmno-proektnyy podkhod, vazhneyshiy instrument regulirovaniya regional'nogo razvitiya [Program and project approach - the most important tool for regulating regional development]. Izvestiya Ural'skogo gosudarstvennogo ekonomicheskogo universiteta, 2008, No. 2 (21), pp. 50-57.

2. Vil'ner M. Ya., O kriteriyakh kachestva skhem territorial'nogo planirovaniya regionov [On the quality criteria of the territorial planning schemes of the regions]. Academia. Arkhitektura i stroitel'stvo, 2012, No. 3, pp. 82-87.

3. Glezer O. B., Sistema mestnogo samoupravleniya kak sostavnaya chast' institutsional'noy sredy rasseleniya $\mathrm{V}$ sovremennoy Rossii [The system of local government as an integral part of the institutional environment of resettlement in modern Russia]. Voprosy geografii, 2013, No. 135, pp. 224-244. 
4. Zamyatina N. Yu., Pilyasov A. N., Regional'nyy konsalting: priglashenie k tvorchestvu. Opyt razrabotki dokumentov strategicheskogo planirovaniya regional'nogo $i$ munitsipal'nogo urovnya [Regional consulting: an invitation to creativity. Experience in developing strategic planning documents at the regional and municipal levels]. SanktPeterburg, Mamatov, 2017, 280 p.

5. Kosmachev K. P., Geograficheskaya ekspertiza (metodologicheskie aspekty) [Geographic expertise (methodological aspects)]. Novosibirsk, Nauka, 1981, 112 p.

6. Kuznetsova O. V., Polnomochiya regionov i munitsipalitetov $\mathrm{v}$ nalogovoy sfere [The powers of the regions and municipalities in the tax sphere]. Problemnyy analiz $i$ gosudarstvenno-upravlencheskoe proektirovanie, 2012, Vol. 5, No. 6, pp. 98-104.

7. Lomsadze D. G., Boldyrikhin A. A., Preodolenie problem tenevoy ekonomiki [Overcoming the problems of the shadow economy]. Voronezh, Ritm, 2018, 77 p.

8. Odintsova A. V., Problemy institutsionalizatsii strategicheskogo planirovaniya munitsipal'nykh obrazovaniy [Problems of institutionalization of strategic planning of municipalities]. Problemy razvitiya territorii, 2018, No. 5(97), pp. 99-109.

9. Nureev R. M., Rossiya posle krizisa, effekt kolei [Russia after the crisis - gauge effect]. Journal of institutional studies, 2011, No. 2, pp. 7-26.

10. Pilyasov A. N., Zamyatina N. Yu., Sravnitel'nyy institutsional'nyy analiz kak novyy instrument issledovaniya problem prostranstvennogo razvitiya [Comparative institutional analysis as a new tool for studying spatial development problems]. Regional'nye issledovaniya, 2012, No. 6, pp. 239-250.

11. Polterovich V. M., Instituty dogonyayushchego razvitiya (k proektu novoy modeli ekonomicheskogo razvitiya Rossii) [Institutions of catching up development (to the draft of a new model of economic development of Russia)]. Ekonomicheskie i sotsial'nye peremeny: fakty, tendentsii, prognoz, 2016, No. 5(47), pp. 34-56.

12. Porosenkov Yu. V., Zadachi i problemy geograficheskogo issledovaniya munitsipal'nykh obrazovaniy Rossiyskoy Federatsii [Tasks and problems of geographical research of municipalities of the Russian Federation]. Vestnik Voronezhskogo gosudarstvennogo universiteta. Ser. Geografiya. Geoekologiya, 2012, No. 1, pp. 5-13.

13. Porosenkov Yu. V., Sushkova O. Yu., Regional'naya skhema razmeshcheniya proizvoditel'nykh sil Voronezhskoy oblasti [The regional layout of the productive forces of the Voronezh region]. Vestnik Voronezhskogo gosudarstvennogo universiteta. Ser. Geografiya. Geoekologiya, 2015, No. 2, pp. 50-57.

Кулаковский Евгений Сергеевич

аспирант кафедры региональной политики и политической географии Института наук о Земле Санкт-Петербургского государственного университета, г. СанктПетербург, E-mail: evgeny.kyl@ yandex.ru
14. Rogozina R. E., Geograficheskie osobennosti protsessov territorial'noy organizatsii rossiyskogo obshchestva na rubezhe $X X-X X I$ vekov [Geographic features of the processes of the territorial organization of Russian society at the turn of the XX-XXI centuries]. Voronezh, 2002, $18 \mathrm{p}$.

15. Sysoeva N. M, Geograficheskaya ekspertiza kak vklad v razvitie institutsional'nogo napravleniya v ekonomicheskoy geografii (k 90-letiyu so dnya rozhdeniya K. P. Kosmacheva) [Geographic expertise as a contribution to the development of the institutional direction in economic geography (on the 90th birthday of K. P. Kosmachev)]. Geografiya i prirodnye resursy, 2011, No. 4, pp. 157-160.

16. Chistobaev A. I., Vladimir Mikhaylovich Chetyrkin, teoretik problemnogo rayonirovaniya [Vladimir Mikhailovich Chetyrkin - theorist of problem zoning]. Izvestiya Russkogo geograficheskogo obshchestva, 2008, No. 5, pp. 1-8.

17. Chistobaev A. I., Prostranstvennoe planirovanie v Rossii: sostoyanie, problemy, zadachi geografov [Spatial planning in Russia: state, problems, tasks of geographers]. Sotsial'no-ekonomicheskaya geografiya. Vestnik Assotsiatsii rossiyskikh geografov-obshchestvovedov, 2013, No. 1, pp. 15-24.

18. Chistobaev A. I., Territorial'naya organizatsiya mestnogo samoupravleniya v Rossii [Territorial organization of local government in Russia]. Geografiya v shkole, 2014, No. 7, pp. 10-17.

19. Chistobaev A. I., Syuzhety iz praktiki upravleniya razvitiem territoriy v SSSR i sovremennoy Rossii [Subjects from the practice of managing the development of territories in the USSR and modern Russia]. Sotsial'no-ekonomicheskaya geografiya. Vestnik Assotsiatsii rossiyskikh geografov-obshchestvovedov, 2018, No. 7, pp. 13-24.

20. Chistobaev A. I., Bazhenov Yu. N., Territorial'nye kompleksnye programmy [Territorial integrated programs]. Leningrad, Leningradskiy gosudarstvennyy universitet, 1984, $228 \mathrm{p}$.

21. Acemoglu D., Robinson J., Why Nations Fail: The Origins of Power, Prosperity, and Poverty, New York, Crown Publishers, 2012, 571 p.

22. North D., Institutions, institutional shanges and economic performance, Cambridge, Cambridge University Press, 1990, 159 p.

23. Martin R., Institutional approaches in economic geography, A companion to economic geography, Oxford, Blackwell, 2000, P. 77-94.

24. Syssoeva N. M. Institutional problems of regional development in Russia, Quaestiones Geographicae, 2010, No. 29, P. 19-25.

25. Wilson D., Institiutions, Encyclopedia of human geography, London, SAGE Publications, 2006, P. 260-261.

Kulakovskiy Evgeniy Sergeyevich

Postgraduate student of the Department of Regional Policy and Political Geography of the Institute of Earth Sciences, St. Petersburg State University, St. Petersburg, E-mail: evgeny.kyl@yandex.ru 